\title{
MULTIPLE MARKETS AND SPATIAL AGGLOMERATION IN A ONE SHOPPING TRIP MODEL
}

\author{
Jose Noguera \\ CERGE-EI, Charles University \\ Politických vězň̀ 7, 11121 Prague 1
}

\begin{abstract}
$\underline{\text { Abstract }}$
This paper analyzes a spatial competitive monopolistic model of agglomeration in which households make only one shopping trip per period, and there are several firms in each industry. The model is a version of a model by Fujita (1988), but unlike his, in this model no equilibrium mixed district is possible, and a number of firm districts may appear. It is shown that allowing several firms in each industry may lead to a Mall equilibrium or an equilibrium with multiple shopping centers.
\end{abstract}

\begin{abstract}
Abstrakt
Článek analyzuje prostorový model monopolistické soutěže v aglomeraci, ve kterém domácnosti nakupují pouze jedenkrát $\mathrm{v}$ každé periodě, a $\mathrm{v}$ každém průmyslovém odvětví působí několik firem. Tento model je variací Fujitova modelu (Fujita, 1988), avšak na rozdíl od něj nevede k rovnovážnému stavu se smíšeným okrskem a umožňuje, aby firemních okrsků bylo $\mathrm{v}$ rovnovážném stavu několik. Působí-li $\mathrm{v}$ každém průmyslovém odvětví několik firem, může nastat Mallův rovnovážný stav nebo rovnovážný stav s několika nákupními centry.
\end{abstract}




\section{MULTIPLE MARKETS AND SPATIAL AGGLOMERATION IN A ONE SHOPPING TRIP MODEL}

Jose Noguera, CERGE-EI

In their excellent survey on urban spatial structures, Anas, Arnott and Small (1998) enumerate several centripetal forces as sources of agglomeration, and summarize some of the main theories explaining the phenomenon. They encompass spatial inhomogeneities, internal scale economies, inter-industry linkages, economies of localization and urbanization, and imperfect competition. This essay deals with the last source of spatial agglomeration. Hotelling (1929) was the first to address this issue. One way in which the problem has been approached is by spatial oligopoly modelling. There is a considerable amount of literature using this approach. In those models, the firm's market power and economies of scale are essential to determine the resulting equilibrium location pattern. Yet, when strategic actions are less important and product variety is the relevant feature, spatial monopolistic competition models seem more adequate to study the topic. In particular, the Dixit and Stiglitz (1977) model has been used by many to derive a number of results on spatial agglomeration. For example, Krugman (1991, 1993) develops a model in which monopolistic competitive firms locate at a single point when transport costs are low. Vickrey (1999) presents important results in spatial competition and monopolistic competition.

Of particular interest in this literature is Fujita (1988). He introduces a land market into a spatial version of the Dixit-Stiglitz model to explain some agglomeration patterns. Although firms tend to cluster in their most convenient 
location, land rent makes them spread out in order to economize on rent. In that model, the interaction between firms and households generates a variety of possible equilibriums. In some of them, land is exclusively used for residential or commercial purposes. Yet, it may also foster the creation of mixed districts where firms and households simultaneously locate. In his model, cities may be either monocentric or polycentric in equilibrium. Rivera-Batiz (1988) and Abdel-Rahman (1988) describe variants of Fujita's model in which firms may not occupy any land. Fujita and Hamaguchi (2001) introduce intermediate goods in a similar model and find a variety of possible patterns.

One critical assumption by Fujita (1988) is the transport cost structure. He assumes that each household makes one trip every time they go to buy something. Fujita justifies the one trip assumption using the restaurant industry. In this paper, we modify Fujita's model to analyze the land use equilibrium when households adopt a different transport strategy. They make only one shopping trip in which they purchase all the goods that they need to acquire. To justify this transport strategy, we may think of the clothing industry. When we go shopping, we not only visit a number of places to buy clothes, but also to buy unrelated goods. Sections I and II state the basic assumptions about the behavior of households and firms. Section III defines the bid rent functions of households and firms, and land use equilibrium. Section IV is concerned with finding and studying the short run land use equilibrium. The long run equilibrium is analyzed in Section V, and Section VI shows some comparative static analysis. Section VII concludes. 


\section{HOUSEHOLD BEHAVIOR}

Assume that there are $M$ representative households living in a city whose location space is given by a set $X$. Each household goes shopping in each period to acquire a continuum of $N$ consumption goods. Let $Y$ be each household's income, which is assumed to be constant and exogenous. Each shop provides a different good, so every household has to visit $N$ different places each time they go shopping. In their shopping trip, households go by car from home to a parking lot located in a central place, $x_{m}$. Then, they make $N$ round trips walking from the parking lot to each of the different shops. Finally, they pick all their purchases from the central place and go back home. Preferences behave according to the following utility function

$$
u=\int_{0}^{N} b(z) d z+z_{0}
$$

where $z$ is the consumption of a good sold at location $z, z \in(0, N)$. Since goods enter symmetrically in the model except for their location, we can identify them by the place the firm operates without any ambiguity. The term $z_{0}$ represents all other expenditures and is taken as numeraire. Notice that goods enter symmetrically into the utility function. Assume that the benefit function, $b$, is an increasing and a strictly concave function of $z$.

Let $t(x, y)$ denote the transport cost for a trip between location $x$ and location $y$ by car, and let $s(x, y)$ denote the transport cost for a trip between location $x$ and location $y$ walking. Assume that all sellers use the same technology, and the only difference among them is location. Thus, all goods provided at the same location have the same equilibrium price, $p(y)$, and each household living at location $x$ buys the same amount, $z(x, y)$, of each good provided at location $y$. We call $z(x, \cdot)$ the spatial 
demand distribution function of a household living at $x$, and equation (1) can be written as

$$
u=\int_{y \in X} b[z(x, y)] f(y) d y+z_{0},
$$

where $f(y)$ is the number of firms located at $y$, as well as the number of goods supplied at that location. Then, $f(y) / N$ is the distribution function of firms. Let $R(x)$ be the market land rent at $x$. Assume, for simplicity, that the amount of land consumed by each household is fixed and equal to unity. The central place, $x_{m}$, must be the expected location of a firm, so

$$
x_{m}=\int_{y \in X} y \frac{f(y)}{N} d y .
$$

The budget constraint of a household living at location $x$ is given by

$$
z_{0}+\iint_{y \in X}\left[s\left(y, x_{m}\right)+p(y)\right] z(x, y) f(y) d y+t\left(x, x_{m}\right)+R(x)=Y .
$$

Thus, the problem for a household living at location $x$ is to choose the amount $z(x, y)$ that it will buy from each firm located at $y$, in order to maximize the utility function (2) subject to the budget constraint (4). Thus, substituting (4) in (2) and rearranging, the utility function of each household will give

$$
u=\int_{y \in X}\left\{b[z(x, y)]-\left[s\left(y, x_{m}\right)+p(y)\right] z(x, y)\right\} f(y) d y+Y-t\left(x, x_{m}\right)-R(x) .
$$

As Fujita (1988), let's specify the benefit function as

$$
b(z)=\left\{\begin{array}{cl}
\frac{z}{\alpha}[1+\log \beta]-\frac{z}{\alpha} \log \left(\frac{z}{\alpha}\right) & \text { if } z<\alpha \beta \\
\beta & \text { if } z>\alpha \beta
\end{array} .\right.
$$

From the maximization problem we obtain

$$
z=\alpha \beta e^{-\alpha\left[s\left(y, x_{m}\right)+p(y)\right]},
$$


and hence

$$
\underset{z(x, y)}{\operatorname{Max} .}\left\{b[z(x, y)]-\left[s\left(y, x_{m}\right)+p(y)\right] z(x, y)\right\}=\beta e^{-\alpha\left[s\left(y, x_{m}\right)+p(y)\right]},
$$

where $y$ represents the location of firms in the last two expressions. Since $Y$ is fixed, we may denote $U(x)=u(x)-Y$, and rewrite the utility function as

$$
U(x)=\int_{y \in X} \beta e^{-\alpha\left[s\left(y, x_{m}\right)+p(y)\right]} f(y) d y-t\left(x, x_{m}\right)-R(x) .
$$

\section{FIRMS}

Assume that all firms use the same technology, have the same fixed cost, $K$, and the same marginal cost, $c$. Let $h(y)$ be the number of households living at location $y$, $(y \in X)$. Assume also that every good is sold only by one firm, and that each firm consumes only one unit of land. Therefore, firms located at $x$ 's profit is

$$
\pi(x)=[p(x)-\mathrm{c}] D(x)-R(x)-K,
$$

where $D(x)$ is the demand for each firm located at $x$. But, each firm located at $x$ receives a demand $z(x, y)$ from a household located at $y$. So, the total demand received by any firm located at $x$ is $D(x)=\int_{y \in X} h(y) z(x, y) d y$, and the firm's profit can be rewritten as

$$
\pi(x)=[p(x)-\mathrm{c}] \int_{y \in X} h(y) z(x, y) d y-R(x) \ell_{\mathrm{f}}-K .
$$

If we define $\Pi(x)=\pi(x)+K$, then

$$
\Pi(x)=[p(x)-\mathrm{c}] \int_{y \in X} h(y) z(x, y) d y-R(x) .
$$

A firm located at $x$ will choose a price $p(x)$ so as to maximize its profits. Thus, using (5) in (7), from first order conditions we get

$$
p(x)=c+1 / \alpha \quad \forall x \in X .
$$


All firms will set the same equilibrium price. Let's then call $p(x)=p$, for all $x \in X$. Substituting this and (5) back on (7), we get

$$
\Pi(x)=[p(x)-\mathrm{c}] \int_{y \in X} \alpha \beta h(y) e^{-\alpha\left[s\left(x, x_{m}\right)+p\right]} d y-R(x) .
$$

Notice that the only term inside the integral that depends of $y$ is $h(y)$, so taking this into account and using (8) we can rewrite this expression as

$$
\Pi(x)=\beta M e^{-\alpha\left[s\left(x, x_{m}\right)+p\right]}-R(x)
$$

Notice from (9), that the firm's profit is not affected by the location of households, but by its distance to the central place, $x_{m}$.

\section{BID RENT FUNCTIONS AND FURTHER SPECIFICATIONS.}

Equations (6) and (9) lead us in a natural way to define the bid rent function for households and firms, $\psi$ and $\phi$ respectively, as follows

$$
\psi\left(x, U, f, x_{m}, p\right)=\int_{y \in X} \beta e^{-\alpha\left[s\left(y, x_{m}\right)+p\right]} f(y) d y-t\left(x, x_{m}\right)-U
$$

$$
\phi\left(x, \Pi, h, x_{m}, p\right)=\beta M e^{-\alpha\left[s\left(x, x_{m}\right)+p\right]}-\Pi
$$

We have the households' bid rent function (11), and given a firm distribution (f), a utility level $(U)$, the central place $\left(x_{m}\right)$, and price $(p)$, it represents the maximum rent per unit of land that the household is willing to pay for residing at location $x$. Likewise, (12) gives the firms' bid rent function, and given a household's distribution $(h)$, a profit level $(\Pi)$, the central place $\left(x_{m}\right)$, and price $(p)$, it represents the maximum rent per unit of land that the firm is willing to pay for locating at $x$.

Definition. A land use equilibrium is a set $\left\{\left(h^{*}(x), f^{*}(x), R^{*}(x), U^{*}, \Pi^{*}\right)\right.$ such that $x \in X$ \} which holds the following conditions: 
$R^{*}(x)=\max \left\{\psi\left(x, U^{*}, f^{*}, x_{m}, p\right), \phi\left(x, U^{*}, h^{*}, x_{m}, p\right), R_{a}\right\}$,

$\psi\left(x, U^{*}, f^{*}, x_{m}, p\right)=R^{*}(x) \quad$ if $h^{*}(x)>0$ and $x \in X$,

$\phi\left(x, \Pi^{*}, h^{*}, x_{m}, p\right)=R^{*}(x) \quad$ if $f^{*}(x)>0$ and $x \in X$,

$h^{*}(x)+f^{*}(x) \leq L(x) \quad$ if $x \in X$,

$h^{*}(x)+f^{*}(x)=L(x) \quad$ if $R^{*}(x)>R_{a}$ and $x \in X$,

$\int_{x \in X} h^{*}(x) d x=M$

$\int_{x \in X} f *(x) d x=N$

(19)

where $L(x)$ denotes the density land distribution, and $R_{a}$ denotes the agricultural rent. Condition (13) means that the market land rent curve, $R^{*}(x)$, is the upper envelope of the equilibrium bid rent curves of households and firms, and the agricultural rent line, $\psi\left(x, U^{*}, f^{*}, x_{m}, p\right)$ and $\phi\left(x, \Pi^{*}, h^{*}, x_{m}, p\right)$ and $R_{a}$ respectively. Condition (14) means that if a household resides at location $x$, then they will pay the rent given by the market rent curve, $R^{*}(x)$. Similarly, condition (15) says the same for firms located at $x$. Condition (16) is a space constraint, i.e., at location $x$, all households and firms residing there cannot use more land than there is available. Condition (17) means that if the market land rent curve at $x$ exceeds the agricultural rent, land at $x$ must be used 
for either, households or firms. Conditions (18) and (19) signify that households and firms locate somewhere in the city.

To simplify the analysis, we keep Fujita's (1988) assumptions and define some notations:

1) The land distribution function is constant and equal to unity, i.e., $L(x)=1$;

2) We specify the transport cost function $t(x, y)$ linear in $|x-y|$, i.e., the transport cost function is defined in such a way that $e^{-a t(x, y)}=1-\tau|x-y|$, where $\tau$ is a positive constant. Similarly, $e^{-a s(x, y)}=1-\sigma|x-y|$.

3) We assume that transportation by "walking" is much more expensive than transportation by "car", that is, $\sigma>\tau$.

4) The location space, $X$, is the interval on the real line given by $(-l, l)$.

5) Since $L(x)=1, M+N<2 l$, and hence, $M+N<1 / \sigma<1 / \tau$. So $\sigma$ and $\tau$ are chosen in such a way that these conditions hold.

From assumption 2 we know that $e^{-a s(x, y)}=1-\sigma|x-y|$, and from assumption (3), $0 \leq \mid x$ $-y \mid \leq 2 l$. So, in order for $e^{-a s(x, y)}$ to be positive, $1-2 \sigma l>0$ or $2 l<1 / \sigma$. This condition is assumed to hold. A similar condition may be found for $\tau$. We also assume that $M$ and $N$ are greater than zero and $p \geq c$. Any other possible situations lack economic interest.

\section{LAND USE EQUILIBRIUM}

We are now ready to study the land use equilibrium. Taking derivatives on the households' bid rent function, (11), with respect to $x$ we have

$$
\frac{\partial \Psi}{\partial x}=-\frac{\partial t\left(x, x_{m}\right)}{\partial x}
$$

Considering that $e^{-a t(x, y)}=1-\tau|x-y|$, we obtain 


$$
\frac{\partial \Psi}{\partial x}=-\frac{\partial t\left(x, x_{m}\right)}{\partial x}= \begin{cases}-\frac{\tau}{\alpha} e^{\alpha t\left(x, x_{m}\right)} & \text { if } x>x_{m} \\ \frac{\tau}{\alpha} e^{\alpha t\left(x, x_{m}\right)} & \text { if } x<x_{m}\end{cases}
$$

and

$$
\frac{\partial^{2} \Psi}{\partial x^{2}}=-\frac{\partial^{2} t\left(x, x_{m}\right)}{\partial x^{2}}=\left\{\begin{array}{ll}
-\frac{\tau^{2}}{\alpha} e^{2 \alpha t\left(x, x_{m}\right)} & \text { if } x>x_{m} \\
-\frac{\tau^{2}}{\alpha} e^{2 \alpha t\left(x, x_{m}\right)} & \text { if } x<x_{m}
\end{array} .\right.
$$

This means that the households' bid rent function is a concave function that reaches a maximum at $x=x_{m}$. However, the function is non-differentiable at this point. Its shape is shown in Figure 1 (See Appendix).

On the other hand, we can write the firms' bid rent function as

$\phi\left(x, \Pi, h, x_{m}, p\right)=\beta M e^{-\alpha p}[1-\sigma|x|]-\Pi$.

This is an increasing straight line with a slope $\beta \sigma M e^{-\alpha p}$ for $x<x_{m}$, a decreasing line with a slope $-\beta \sigma M e^{-\alpha p}$, for $x>x_{m}$, and non differentiable at $x=x_{m}$. See Figure 2 (See Appendix).

By overlapping Figures 1 and 2, it is apparent that the land use equilibrium can be any of the three patterns, A, B or C, as shown in Figures 3, 4 and 5 respectively (See Appendix). In pattern $\mathrm{A}$, the city is located inside the interval $(-b, b)$. Interval $(-a$, a) forms an exclusive firm district (FD), and intervals $(a, b)$ and $(-b,-a)$ form exclusive residential districts (RD). Pattern B shows exactly the opposite case, interval $(-a, a)$ forms a residential district and $(a, b)$ and $(-b,-a)$ form two exclusive firm districts. In this analysis, we have assumed that the central place is $x_{m}=0$.

Consider pattern A, where a Central Business District exists. Notice that in this case, $f(x)=1$, for $x \in(-a, a)$ and zero otherwise, and $h(x)=1$ for $x \in(-b,-a)$ or $x \in(a$, 
$b)$, and zero otherwise. Hence, from (18) and (19) we obtain $a=N / 2$ and $b=(M+$ N)/2. Now,

$$
\int_{N / 2}^{(M+N) / 2} e^{-\alpha[s(0, x)+p]} d y=\left(\frac{M}{2}\right) e^{-\alpha[s(0, x)+p]}=\left(\frac{M}{2}\right)(1-\sigma|x|) .
$$

Substituting this back in (20), we get

$$
\phi^{*}\left(x, \Pi^{*}, p\right)=\gamma M(1-\sigma|x|)-\Pi^{*},
$$

where $\gamma=\beta e^{-\alpha p}$. Since $p, c, \alpha, \gamma, M$, and $\sigma$ are given, (21) gives an expression of the firms' bid rent as a function of locations and the equilibrium profit, $\Pi^{*}$. On the other hand, we can write the households' bid rent function as

$$
\psi^{*}\left(x, U^{*}, p\right)=\mathrm{N} \gamma(1-\sigma N / 4)+\frac{1}{\alpha} \log (1-\tau|x|)-U^{*}
$$

But, in pattern A, we know that $\psi\left(b, U^{*}, p\right)=\psi\left[(M+N) / 2, U^{*}, p\right]=R_{a}$. Thus, from (22)

$$
U^{*}=\mathrm{N} \gamma(1-\sigma N / 4)+\frac{1}{\alpha} \log \left(1-\frac{\tau}{2}(M+N)\right)-R_{a}
$$

Substituting (23) in (22)

$$
\psi^{*}(x, p)=\frac{1}{\alpha} \log \left(\frac{1-\tau|x|}{1-\frac{\tau}{2}(M+N)}\right)+R_{a}
$$

Now, we have $\psi^{*}(\mathrm{~N} / 2, p)=(1 / \alpha)[\log (1-\tau N / 2)-\log (1-\tau(N+M) / 2)]+R_{a}$, and also $\phi^{*}\left(\mathrm{~N} / 2, \Pi^{*}, p\right)=\gamma M(1-\sigma N / 2)-\Pi^{*}$. Yet, $\psi^{*}(\mathrm{~N} / 2, p)=\phi^{*}\left(\mathrm{~N} / 2, \Pi^{*}, p\right)$, so 


$$
\Pi^{*}=\gamma M(1-\sigma N / 2)-\frac{1}{\alpha} \log \left(\frac{1-\tau N / 2}{1-\frac{\tau}{2}(M+N)}\right)-R_{a}
$$

Substituting (25) back in (21), we obtain

$$
\phi^{*}(x, p)=\gamma M \sigma\left(\frac{N}{2}-|x|\right)+\frac{1}{\alpha} \log \left(\frac{1-\tau N / 2}{1-\frac{\tau}{2}(M+N)}\right)+R_{a} .
$$

Since $\alpha, \gamma, M, N, \tau, \sigma$ and $R_{a}$, are given, expressions (24) and (26) give the bid rent functions of households and firms in terms of only one exogenous variable, their location, $x$. Notice that if pattern $\mathrm{A}$ is the land use equilibrium, then $\phi^{*}(0, p)>\psi^{*}(0$, p). Thus

$$
\frac{\gamma \sigma M N}{2}+\frac{1}{\alpha} \log (1-\tau N / 2)>0
$$

Clearly, the first term in this inequality is non-negative. Now, notice that $1 / \tau>1 / \sigma>$ $M+N>N / 2$, so $1>1-\tau N / 2>0$, and $\log (1-\tau N / 2)<0$. Therefore, the last inequality holds if and only if $(\gamma \sigma M N / 2)>e^{\alpha_{p}} \log \left[(1-\tau N / 2)^{-1 / \alpha}\right]$, so

$$
e^{\alpha p}<\varphi(M, N, \sigma, \tau, \beta)
$$

where $\varphi(M, N, \sigma, \tau, \beta)=\frac{\beta \sigma M N}{2 \log \left[(1-\tau N / 2)^{-1 / \alpha}\right]}$. Inequality (27) is a necessary condition for pattern A to exist, i.e., the existence of a CBD. Intuitively, this condition simply establishes that the "peak" of the firms' bid rent function is higher than the maximum of the household's. Notice that this discards pattern $\mathrm{C}$ but not pattern B. 
Let's now turn to pattern C. This case is illustrated by Figure 5 (See Appendix). Now, $a=M / 2$ and $b=(M+N) / 2$, so the firms' bit rent function is again as in (21). However, the households' bid rent function changes to

$$
\psi^{*}\left(x, U^{*}, p\right)=N \gamma\left(1-\frac{\sigma(N+2 M)}{4}\right)+\frac{1}{\alpha} \log (1-\tau|x|)-U^{*}
$$

From Figure 5, notice that $\phi^{*}[(M+N) / 2, p]=R_{a}$, so from (21) we have

$$
\Pi^{*}=\gamma M\left(1-\frac{\sigma}{2}|M+N|\right)-R_{a}
$$

and hence

$$
\phi^{*}(x, p)=\sigma \gamma M\left(\frac{M+N}{2}-|x|\right)+R_{a}
$$

Since now households form a residential district at the center of the city, $\phi^{*}=\psi^{*}$ when $x=M / 2$, but $\phi^{*}(M / 2, p)=\sigma \gamma M N / 2+R_{a}$ and $\psi^{*}\left(\mathrm{M} / 2, U^{*}, p\right)=N \gamma[1-\sigma(N+2 M) / 4]+$ $(1 / \alpha) \log (1-\tau M / 2)-U^{*}$. Thus, using this in (8) we obtain the equilibrium utility level

$$
U^{*}=N \gamma\left(1-\frac{\sigma(N+2 M)}{4}\right)+\frac{1}{\alpha} \log \left(1-\frac{\tau M}{2}\right)-\sigma \gamma M N / 2-R_{a}
$$

Therefore, we can write the households' bid rent function as

$$
\psi^{*}(x, p)=\frac{1}{\alpha} \log \left(\frac{1-\tau|x|}{1-\tau M / 2}\right)+\gamma \sigma M N+R_{a}
$$

Then, (29) and (31) give the bid rent functions of firms and households in case of pattern C. Notice that this equilibrium only holds if $\phi^{*}(0, p)<\psi^{*}(0, p)$, and this happens only if 


$$
e^{\alpha p}>\varphi(M, N, \sigma, \tau, \beta)(1-M / N)
$$

This inequality characterizes land use equilibrium in pattern C. Notice that, if $M$ is very large with respect to $N, M / N$ tends to zero. In other words, if the number of households is very large in comparison with the number of firms, the resulting land use equilibrium pattern depends on whether $e^{\alpha p}$ is less or greater that $\varphi(M, N, \tau, \beta)$ respectively. Let's study this relation more carefully. Consider first the particular case when $M / N$ tends to zero, so $e^{\alpha p}<\varphi$ implies pattern A and $e^{\alpha p}<\varphi$ pattern C. Given $M, N, \tau$, and $\beta$, the price level, $p$, determines the pattern. This is illustrated in Figure 6 (See Appendix). For prices below $p^{*}\left(p<p^{*}\right)$, pattern A is the only possible land use equilibrium. On the other hand, pattern B occurs for prices above $p^{*}\left(p>p^{*}\right)$. An interesting case is when $\varphi$ is so small that $e^{\alpha p}>\varphi$ for all prices. In this case, pattern $\mathrm{B}$ always occurs, as illustrated in Figure 7 (See Appendix).

Let's turn to the general case, and let $M / N$ take any finite positive number. As before, only pattern A can be an equilibrium for $p<p^{*}$, and only pattern B for $p>p^{*}(1$ $-M / N)$. However, there is also the case $p^{*}(1-M / N)<p<p^{*}$, in which both patterns result in a land use equilibrium. This case is illustrated in Figure 8 (See Appendix).

The explanation for these results is as follows. Both, households and firms have preferences for being located as centrally as possible, so they are willing to pay more rent if they locate more centrally, but this willingness increases as prices lower. Firms, because they want the demand for their products to increase, and households, because their purchasing power increases. Consequently, they both can now pay more in transportation. However, firms become willing to pay even more than households as prices decrease, so for lower prices, firms pay more rent for being located at the center and pattern A appears. The opposite case occurs for high prices. To see this, 
observe that the derivative of the bid rent function with respect to the price at $\mathrm{x}=0$. Although this is negative for both, their absolute value is higher for firms than for households. Indeed,

$$
\left|\frac{\partial \phi(x=0)}{\partial p}\right|=\alpha \beta M e^{-\alpha p}>\alpha \beta e^{-\alpha p} \int_{y \in X} e^{-\alpha t(y, 0)} f(y) d y=\left|\frac{\partial \psi(x=0)}{\partial p}\right|,
$$

and this occurs only if

$$
M-N>0>-\tau \int_{y \in X}|y| f(y) d y .
$$

This inequality always holds since $M>N$ by assumption, and the land use equilibrium follows pattern $\mathrm{A}$ for low prices and pattern $\mathrm{C}$ for high prices. However, there exists a fringe where prices are "not so high and not so low", when both patterns of land use equilibrium may occur, this is for $p^{*}(1-M / N)<p<p^{*}$. This is the case for pattern B.

\section{LONG RUN LAND USE EQUILIBRIUM.}

Assume now that there is free entry of firms and let's turn to analyze the long run equilibrium. This assumption requires that firms have zero profits, so $\pi^{*}=\Pi^{*}-\mathrm{K}=0$. In case of pattern $\mathrm{A}$, the long run equilibrium number of firm, $N^{*}$, occurs when $\omega\left(N^{*}\right)=\xi\left(N^{*}\right)$, where

$$
\omega(N)=\gamma M(1-\tau N / 2) \text { and } \quad \xi(N)=\frac{1}{\alpha} \log \left(\frac{1-\tau N / 2}{1-\frac{\tau}{2}(M+N)}\right)+R_{a}+K .
$$

It is apparent that $\omega(N)$ is a negative sloped straight line and $\xi^{\prime}(N)$ and $\xi^{\prime \prime}(N)$ are both negative. So $N$ is given by the intersection of both curves as shown in Figure 9 (See Appendix). Notice that this equilibrium exits only if $\xi(0)>M \gamma$, that is

$$
-\frac{1}{\alpha} \log \left(1-\frac{\tau M}{2}\right)+R_{a}+K>\beta M e^{-\alpha p}
$$


From Figure 9, it is apparent that the higher the agricultural rent, $R_{a}$, or fixed cost, $K$, and the lower $\alpha$, the higher the long run equilibrium number of firm to $N^{* *}$ is, since it translates $\xi$ curve upward up to $\xi 1$. However, both $\omega$ and $\xi$, are increasing with respect to $M$, so its net effect on $N^{*}$ remains unclear. Now in the case of pattern B, $\pi^{*}$ $=0$ if

$$
N^{*}=\frac{2}{\tau}\left(1-\frac{R_{a}+K}{M \beta} e^{\alpha p}\right)-M
$$

For (32) to represent an equilibrium, it is necessary that $N^{*}>0$, and this happens only if $1>\left(R_{a}+K\right) e^{\alpha p} / \beta M+\tau M / 2$. Yet, $1>(M / 2) /(M+N)>\tau M / 2$, since $M+N<1 / \tau$. Thus, we have

$$
0<\frac{R_{a}+K}{M \beta} e^{\alpha p}<1-\frac{M \tau}{2}
$$

This means that, for pattern $\mathrm{C}$ to be a long run equilibrium, prices cannot be excessively high. On the other hand, contrary to the case of pattern A, it is apparent from (32) that an increase in either agricultural rent or fixed cost make the long run number of firms decrease. The effect of a population change is not clear.

\section{SOME COMPARATIVE STATICS}

Let $U_{A}$ and $U_{C}$ denote the equilibrium utility for patterns $\mathrm{A}$ and $\mathrm{C}$, respectively. These are given by (23) and (30). From these expressions it is apparent that equilibrium utility decreases as agricultural rent increases. Taking derivatives respect to $\tau$ and $M$ we get

$$
\frac{\partial U_{A}}{\partial \tau}=-\mathrm{N} \gamma \tau N / 4-\frac{1}{\alpha} \frac{(M+N) / 2}{1-\tau(M+N) / 2}<0
$$




$$
\begin{aligned}
& \frac{\partial U_{C}}{\partial \tau}=-N \gamma \frac{N+2 M}{4}-\frac{1}{\alpha} \frac{M / 2}{1-\tau M / 2}-\gamma M N / 2<0, \\
& \frac{\partial U_{A}}{\partial M}=-\frac{1}{\alpha} \frac{\tau / 2}{1-\tau(M+N) / 2}<0, \quad \text { and } \\
& \frac{\partial U_{C}}{\partial M}=-N \gamma \tau / 2-\frac{1}{\alpha} \frac{\tau / 2}{1-\tau M / 2}-\tau \gamma N / 2<0 .
\end{aligned}
$$

From these expressions it is clear that an increase in both population and transport cost make the equilibrium utility level decrease. Let's analyze now the firm' profit. From (25) and (28) we have equilibrium profits for patterns A and C. Let's denote them $\pi_{\mathrm{A}}$ and $\pi_{\mathrm{C}}$, respectively. As in the previous case, it is apparent that profits decrease as agricultural rent increases. Taking derivatives with respect to $\tau$ and $M$, and a bit of algebra, we have

$$
\begin{aligned}
& \frac{\partial \pi_{A}}{\partial \tau}=-\gamma M N / 2-\frac{1}{2 \alpha}\left[\frac{M}{(1-\tau N / 2)(1-\tau(M+N) / 2)}\right]<0, \\
& \frac{\partial \pi_{C}}{\partial \tau}=-\gamma M(M+N) / 2<0, \\
& \frac{\partial \pi_{A}}{\partial M}=\gamma(1-\tau N / 2)-\frac{1}{\alpha} \frac{\tau}{2-\tau(M+N)}, \quad \text { and } \\
& \frac{\partial \pi_{C}}{\partial M}=\gamma \tau(1 / \tau-(M+N) / 2)>0 .
\end{aligned}
$$

It is clear from these expressions that an increase in transportation cost makes profits decrease. On the other hand, in case of pattern A, a population increase makes the firm's profit also increase, but the effect on pattern $\mathrm{C}$ remains unclear. The reason for this behavior is the following. In both cases, a greater population creates a greater demand. Nevertheless, the more the population, the higher the rent paid by households, the less the income available for other expenditure. The latter effect, 
which appears in pattern A as can be readily see from (25), does not occur in pattern C, as follows from (28).

Consider now the land rent functions. Household's bid rent functions in case of pattern A and C are given by (24) and (31) respectively, and firms' by (26) and (29). It is apparent that an increase in agricultural rent makes each bid rent function increase along with land rent functions. Taking the derivatives on the bid rent functions with respect to $\tau$ in both patterns, we have

$$
\begin{aligned}
& \frac{\partial \psi_{A}}{\partial \tau}=\frac{1}{\alpha}\left(\frac{(M+N) / 2}{1-\tau(M+N) / 2}\right)>0, \\
& \frac{\partial \phi_{A}}{\partial \tau}=\gamma M\left(\frac{N}{2}-|x|\right)+\frac{1}{\alpha}\left(\frac{M / 2}{(1-\tau N / 2)(1-\tau(M+N) / 2)}\right)>0, \\
& \frac{\partial \psi_{C}}{\partial \tau}=-\frac{1}{\alpha} \frac{\tau}{1-\tau|x|}+\frac{1}{\alpha} \frac{M / 2}{1-\tau M / 2}+\gamma M N, \text { and } \\
& \frac{\partial \phi_{C}}{\partial \tau}=\gamma M\left(\frac{M+N}{2}-|x|\right)>0 .
\end{aligned}
$$

The sign of $\partial \Psi_{c} / \partial \tau$ is not clear. In case of pattern $\mathrm{A}$, an increase in transportation cost raises both bid rent functions. Since it is more expensive for households to transport from one place to another, they become more encouraged to locate centrally. Firms respond to this attitude by increasing their bid rent curve. However, in the case of pattern $\mathrm{C}$, this effect is not clear on households since they are already located in the middle.

Finally, we study how an increase in population affects the land rent functions. Taking derivatives on the bid rent function for patterns $A$ and $C$ with respect to $M$, we obtain,

$$
\frac{\partial \psi_{A}}{\partial M}=\frac{1}{\alpha}\left(\frac{\tau / 2}{1-\tau(M+N) / 2}\right)>0
$$




$$
\begin{aligned}
& \frac{\partial \phi_{A}}{\partial M}=\gamma \tau\left(\frac{N}{2}-|x|\right)+\frac{1}{\alpha}\left(\frac{\tau / 2}{(1-\tau(M+N) / 2)}\right)>0, \\
& \frac{\partial \psi_{C}}{\partial M}=\frac{1}{\alpha} \frac{\tau / 2}{1-\tau M / 2}+\gamma \tau N>0, \text { and } \\
& \frac{\partial \phi_{C}}{\partial M}=\gamma \tau(M+N / 2-|x|)>0 .
\end{aligned}
$$

As we can readily see, an increase in population makes the land rent function increase in every case.

\section{SEVERAL FIRMS PER INDUSTRY}

In this section, we explore the case when there are two firms per industry. The reader can figure out a situation in which each firm has two identical stores whose only difference is location. You may consider a chain of restaurants like Burger King or stores like Walmart. Suppose first that each of them has only two stores. In this case, all stores may wish to locate around a unique central place or in the same "shopping center", where the bid rent functions own a maximum, as in Figure 2; but they also could be interested in locating together in two different shopping centers, with bid rent functions owning two maximums, as in Figure 10 below (See Appendix). Let $x_{m}$ and $x_{m}$ ' represent two different central places. Since all firms in each industry sell the same homogeneous good, if each "shopping center" has one firm of each industry, households will go shopping to the closer "shopping center" to buy all they need. In this case, it is easy to check that in equilibrium, the central place of each shopping center is located at the same distance from the city center, as shown in Figure 10. Otherwise the farther located shopping center would have an incentive to move. So assume that $x_{m}$ and $x^{\prime}{ }_{m}$ represent the same distance from 0 , i.e., $x_{m}=-x^{\prime}{ }_{m}$, and hence, 
each shopping center trades to half of the total households living in the city (Figure $10)$.

Regarding to households, their bid rent functions have a maximum at the central location $x_{m}$. Yet, we have now two identical stores per industry and households will go to the closer shopping center, so their bid rent functions have now two maximums making the land rent function look as it is shown in Figure 11 (See Appendix), and two shopping centers or Malls may appear in the city ${ }^{1}$.

Both equilibriums, represented by Figures 3 and 11, are Nash equilibriums since neither household is willing to locate on a firm's district nor a firm on a residential district.

\section{CONCLUSION.}

This paper modifies Fujita's (1988) model to setup a spatial agglomeration model in which households do one shopping trip per period. Households go first from home to a central place to park and after, they make as many trips as necessary from this central place for the goods they need to purchase. As in Fujita (1988), prices in this model are constant and independent of location. Yet, unlike Fujita's model, no equilibrium mixed district results. It is shown that, if there is only one firm per industry and consumption prices are small enough, a Central Business District arises. Yet, if prices are high, households may need to go to several districts. It is also shown that, when there are several firms per industry, a Mall equilibrium with several shopping centers may appear.

Like Fujita (1988), this model still makes a number of assumptions that may appear restrictive. Several alternative transport strategies may be adopted. For 
example, households might stop in one or several shops "on the way", or make several trips to visit different malls, i.e., they might not need to make all purchases in one trip. These extensions may provide more realistic models that allow a better understanding of the spatial agglomeration patterns.

\section{REFERENCES.}

Abdel-Rahman, H. M. (1988). "Product Differentiation, Monopolistic Competition and System of Cities". Regional Science and Urban Economics. 18, North Holland.

Anas, A., R.J. Arnott and K.A. Small (1998). "Urban Spatial Structure," Journal of Economic Literature, pp. 1426-1464.

Dixit, A. K. and Stiglitz, J. E. (1977). "Monopolistic Competition and Optimum Product Diversity”, American Economic Review, 67, 297-308.

Fujita, M. (1988). “A Monopolistic Competition Model of Spatial Agglomeration. Differentiated Product Approach”. Regional Science and Urban Economics, 18, 87-124. North Holland.

Fujita, M. and N. Hamaguchi (2001). "Intermediate Goods and the Spatial Structure of an Economy." Regional Science and Urban Economics. 31:1, pp. 79-109. February.

Hotelling, H. (1929). “Stability in Competition,” Economic Journal. 39:1, pp. 207-29.

Krugman, P. (1991). "Increasing Returns and Economic Geography", Journal of Political Economy, 99:3, pp. 483-499.

Krugman, P. (1993). "First Nature, Second Nature and Metropolitan Location", Journal of Regional Science, 33, 129-144.

\footnotetext{
${ }^{1}$ This is not the only new possible equilibrium. By making a similar analysis, we may have another
} 
Rivera-Batiz, F. L. (1988). "Increasing Returns, Monopolistic Competition and Agglomeration Economies in Consumption and Production”. Regional Science and Urban Economics, 18, 125-153. North Holland.

Vickrey, W. (1999). "Spatial Competition, Monopolistic Competition, and Optimal Product Diversity." International Journal of Industrial Organization, 17(7), October, pp. 953-963.

equilibrium where firms locate at both ends of the city, and households in between. 
Figure 1: Household Bid Rent Function

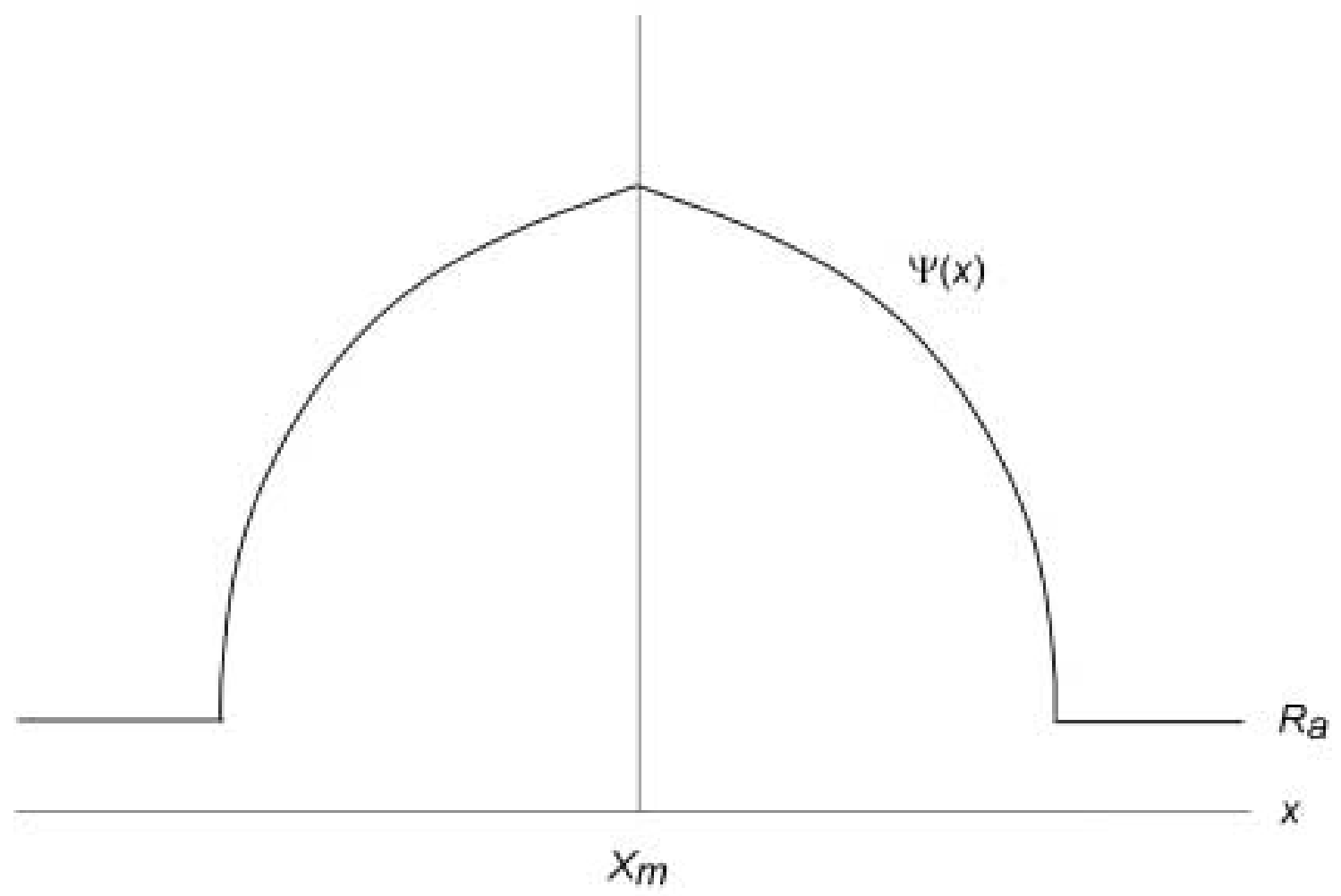

Figure 2: Firm Bid Rent Function

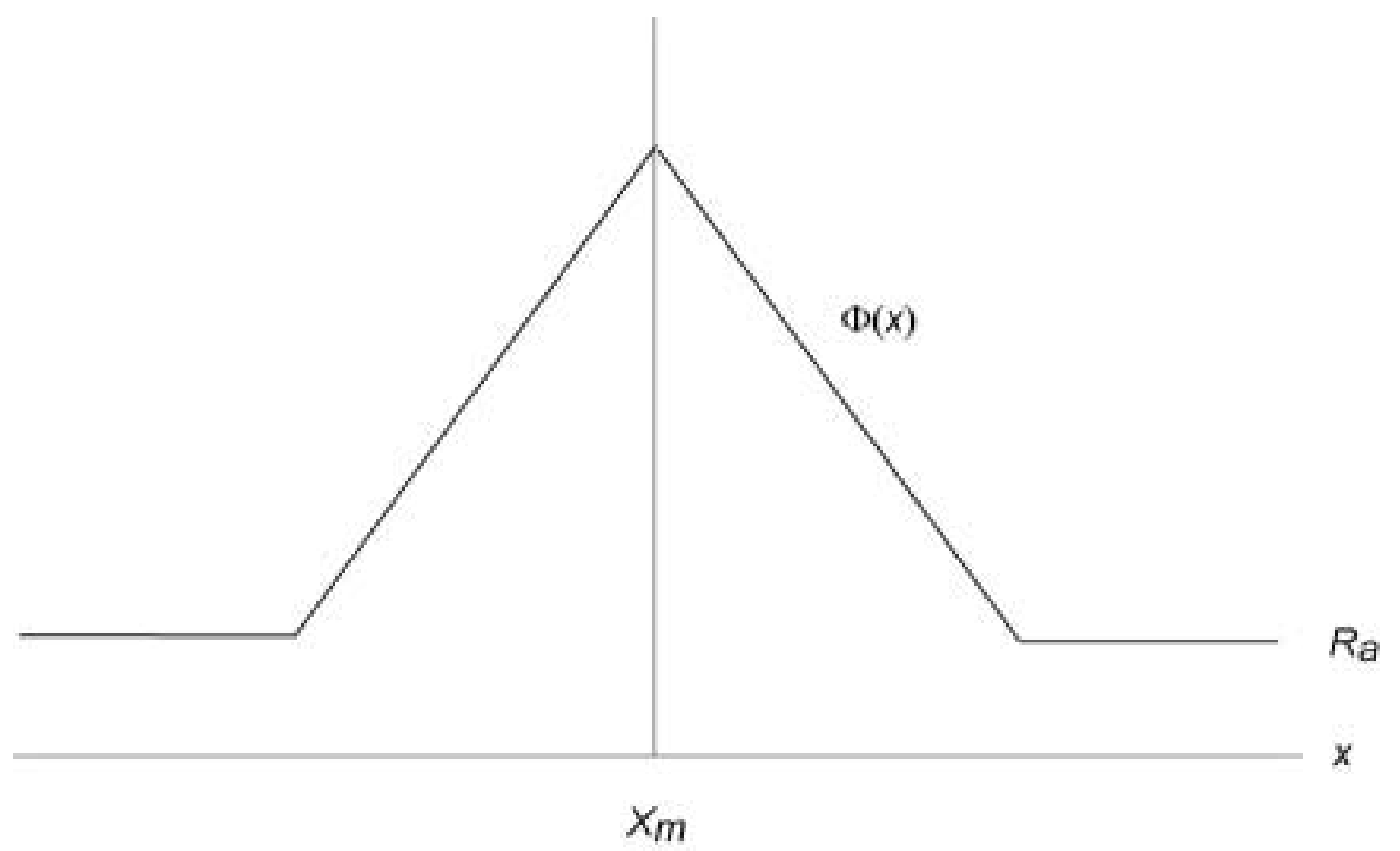


Figure 3: Land use Equilibrium. Pattern A.

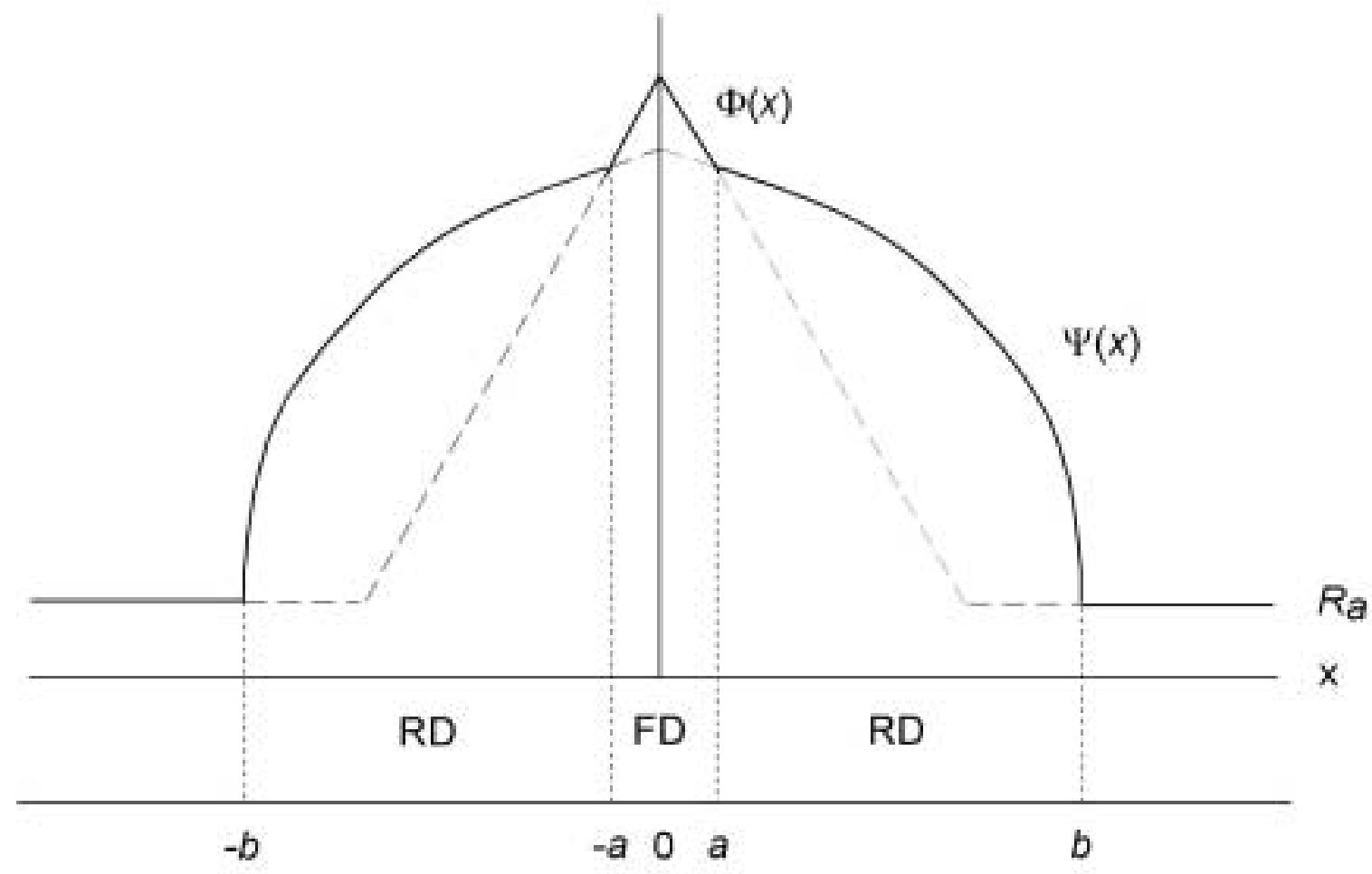

Figure 4: Land Use Equilibrium. Pattern B.

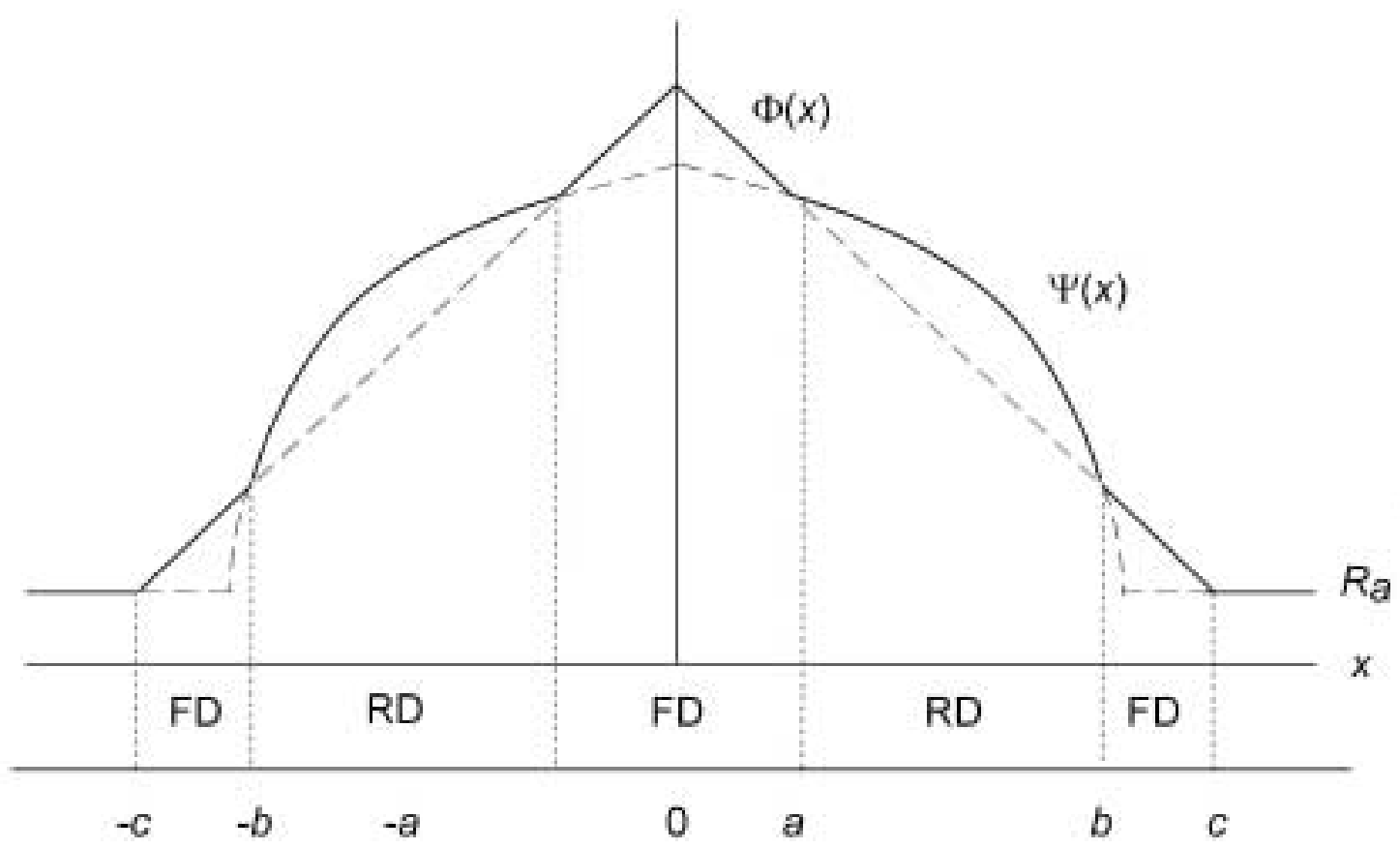


Figure 5: Land Use Equilibrium. Pattern C.

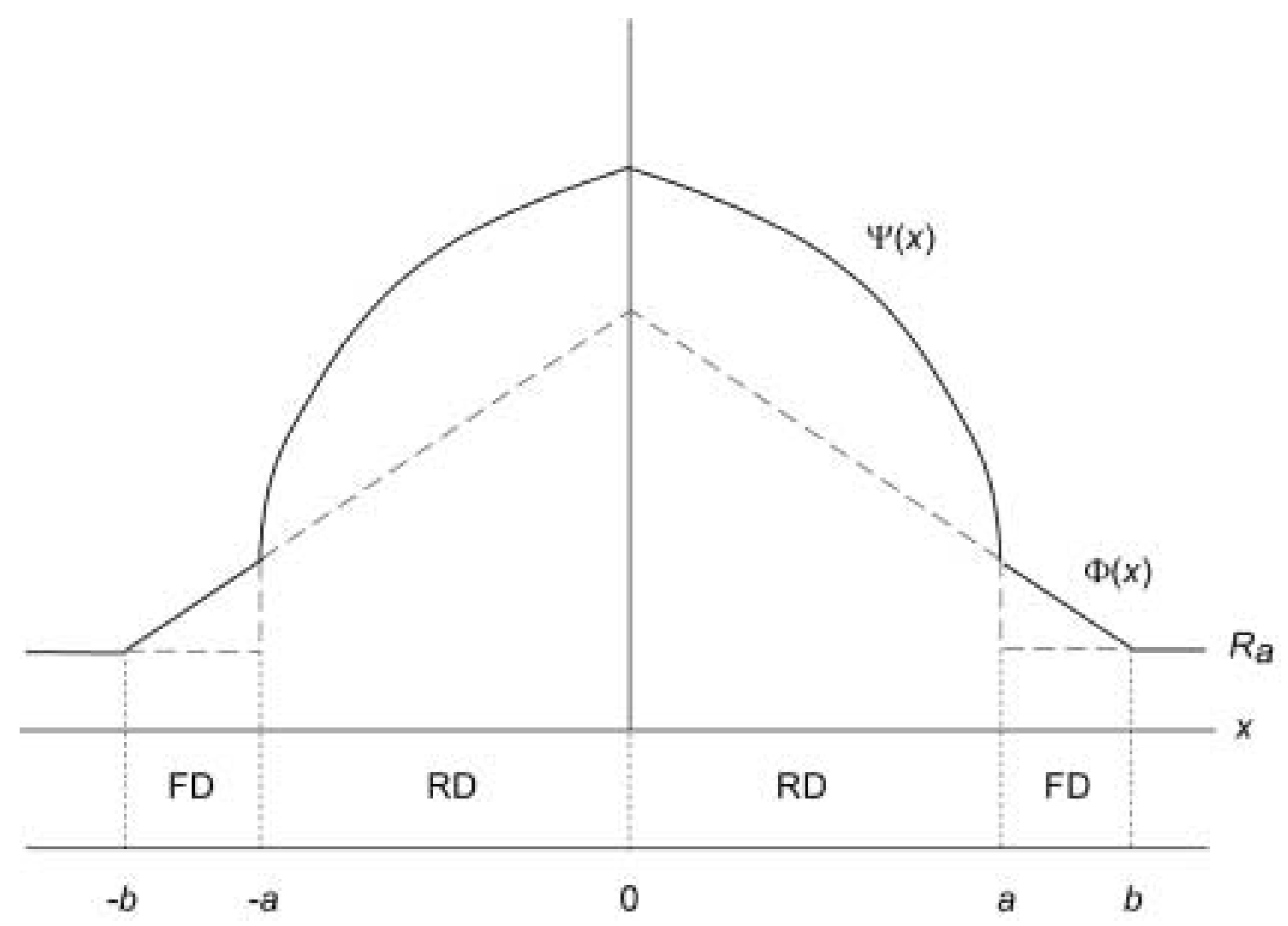

Figure 6: Price Range for Pattern Determination. Particular Case.

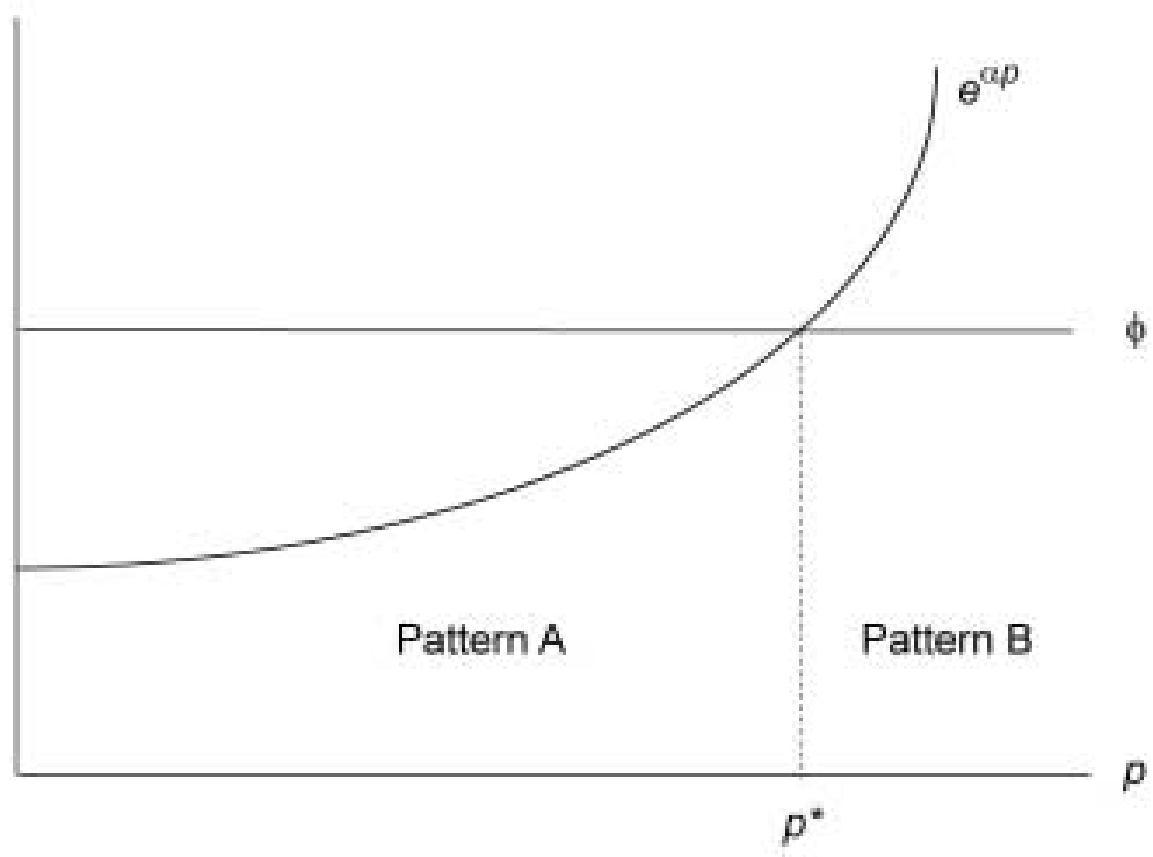


Figure 7: No Pattern A for any Price Range.

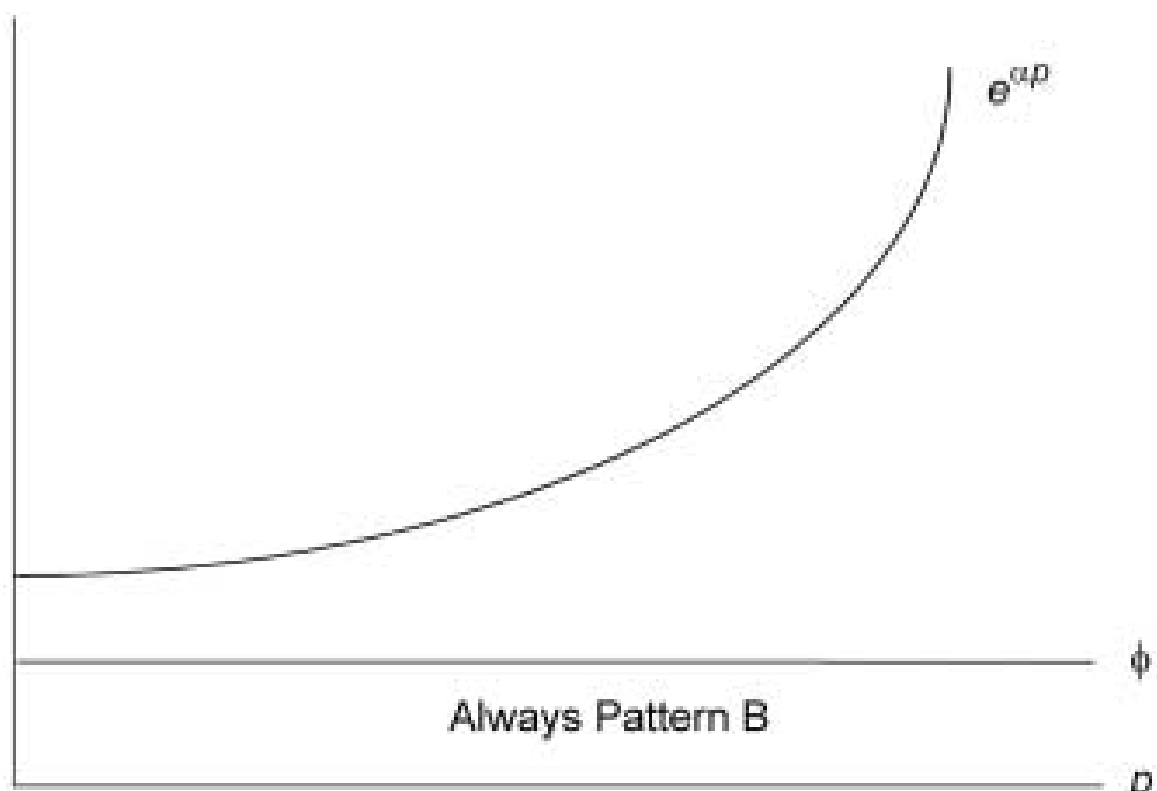

Figure 8: Price Range for Pattern Determination. General case.

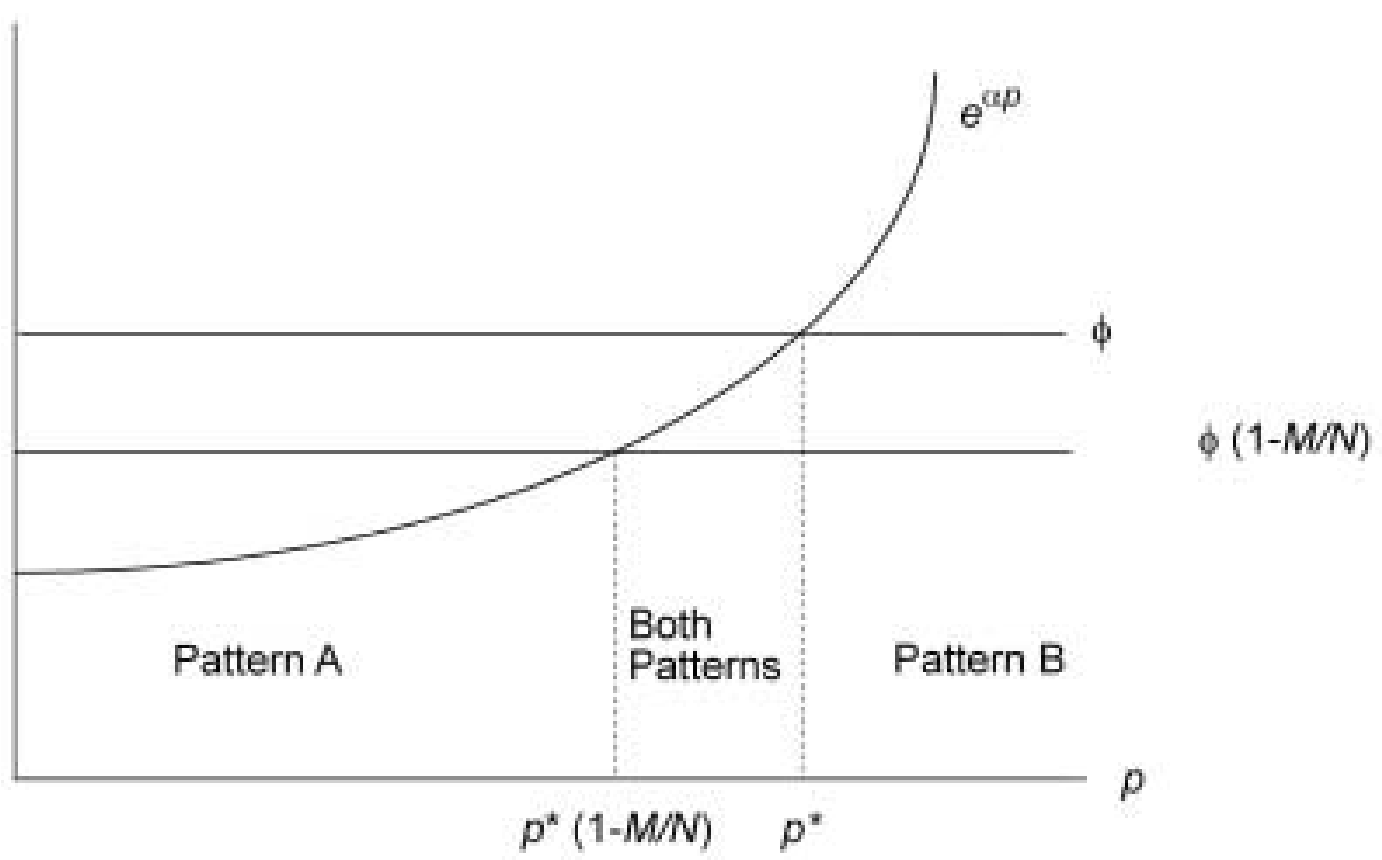


Figure 9: Long Run Equilibrium under Pattern A.

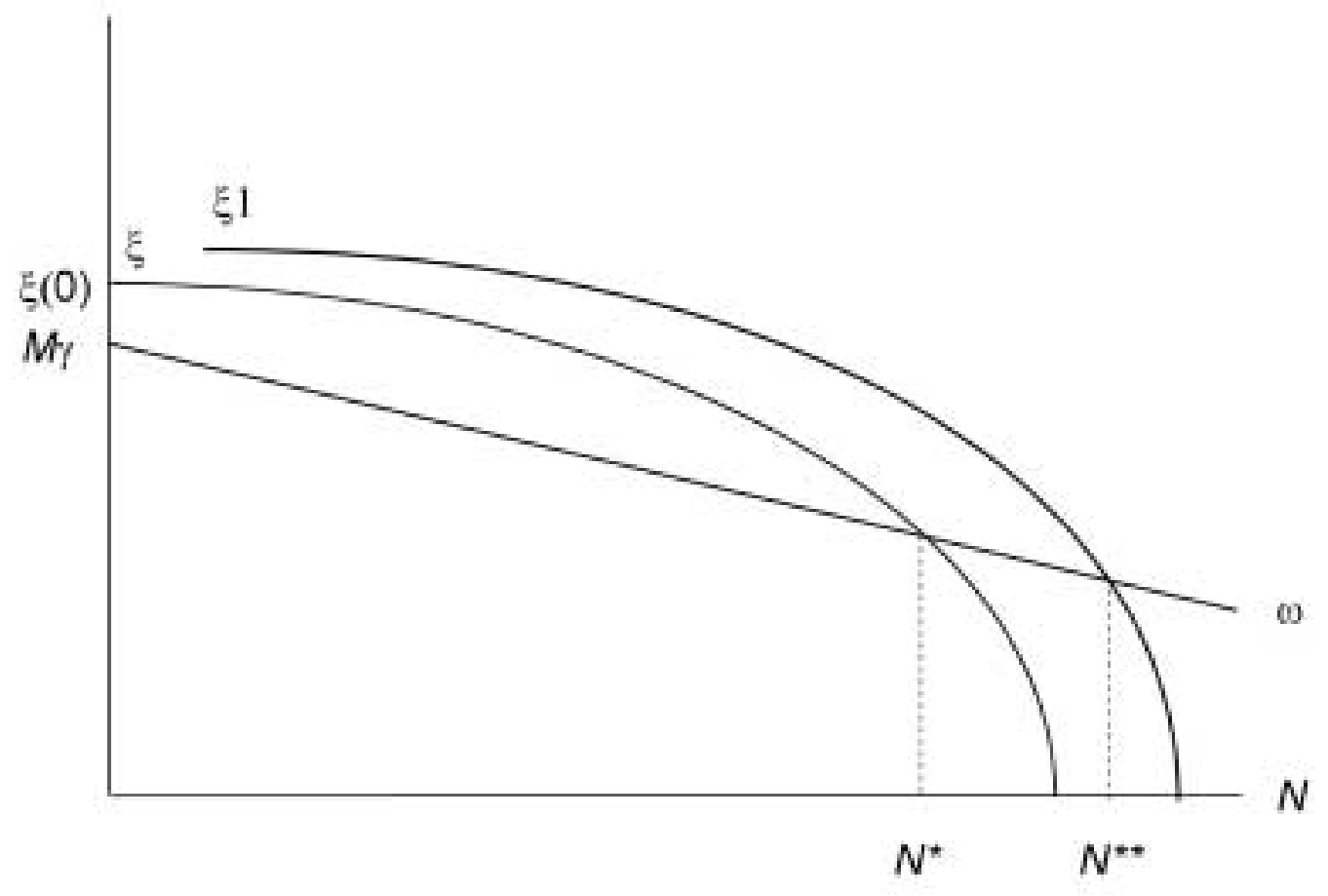

Figure 10: Firm Bid Rent Function with two Firms per Industry

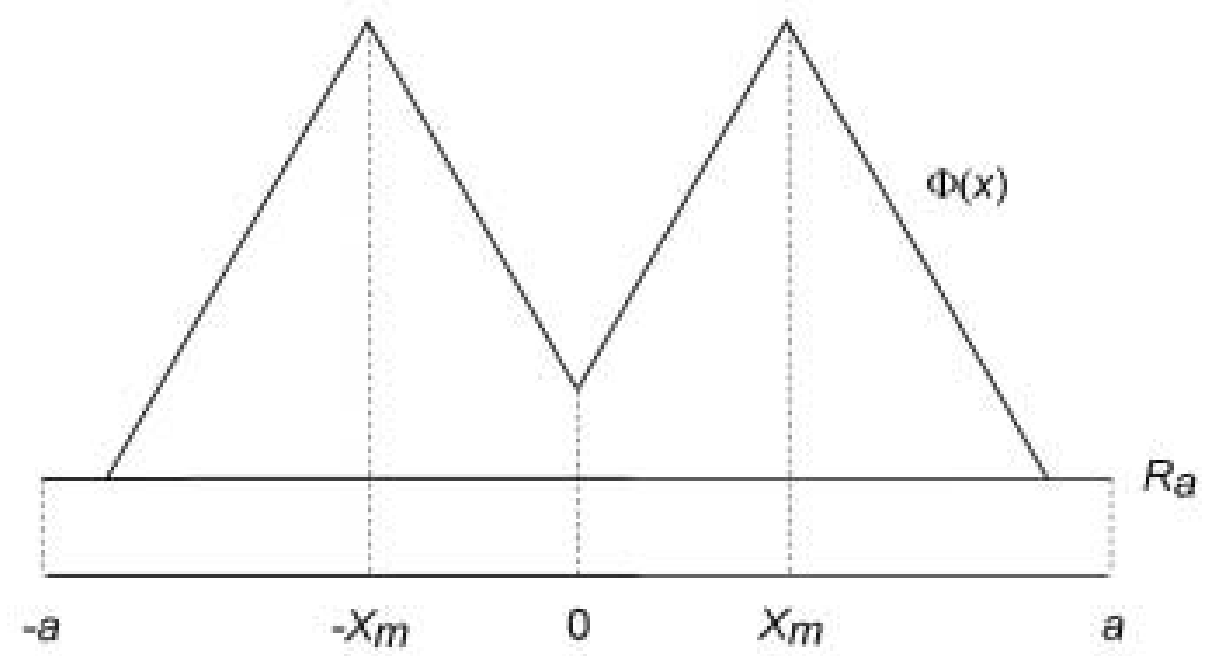


Figure 11: Land Use Equilibrium with several Firms per Industry

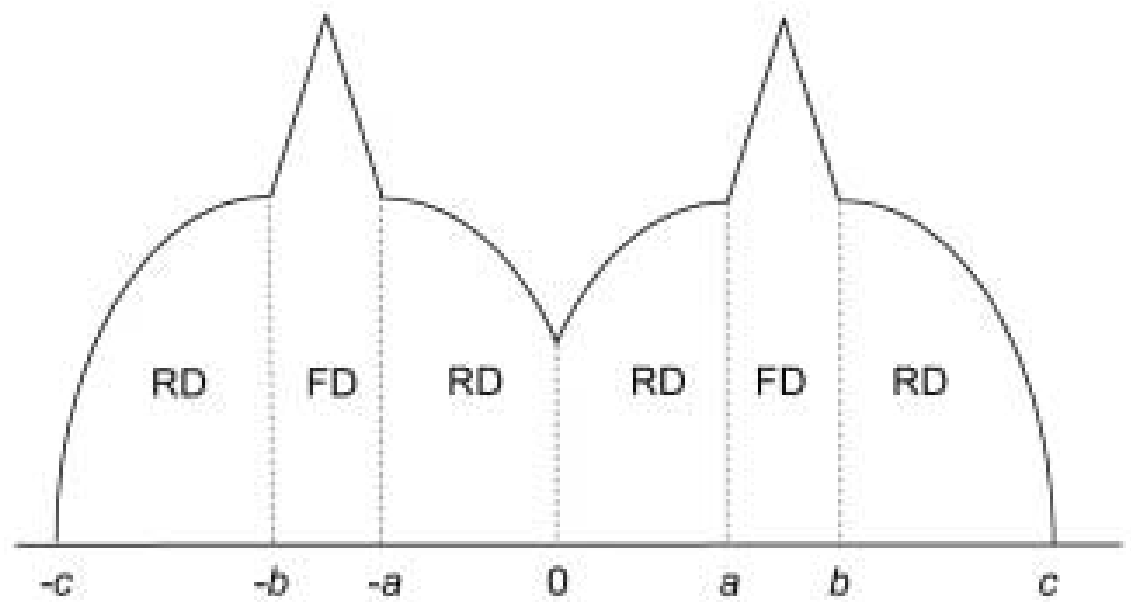

